\title{
THE INFLUENCE OF PRESERVATION ON FISH MORPHOLOGY IN MUSEUM COLLECTIONS BASED ON TWO SPECIES OF THE GENUS LEPOMIS (ACTINOPTERYGII: PERCIFORMES: CENTRARCHIDAE)
}

\author{
Kevin A. GASTON ${ }^{1}$, Stephen J. JACQUEMIN ${ }^{2}$, and Thomas E. LAUER ${ }^{1 *}$ \\ ${ }^{1}$ Department of Biology, Aquatic Biology and Fisheries Center, Ball State University, Muncie, IN 47306, USA \\ ${ }^{2}$ Department of Biological Sciences, Dwyer Hall, Wright State University, Lake Campus, Celina, OH 45822, USA
}

Gaston K.A., Jacquemin S.J., Lauer T.E. 2013. The influence of preservation on fish morphology in museum collections based on two species of the genus Lepomis (Actinopterygii: Perciformes: Centrarchidae). Acta Ichthyol. Piscat. 43 (3): 219-227.

\begin{abstract}
Background. The wide availability of specimen-based museum collections allows scientists to address a variety of ecological and systematic hypotheses from a broad timeframe and extensive spatial scale. However, techniques employed to preserve and maintain these collections affect morphology, potentially altering or skewing any morphological comparisons inherent in research study questions. The purpose of this study was to better understand and describe the effects that preservation techniques may have on fish specimens.

Materials and methods. Bluegill, Lepomis macrochirus Rafinesque, 1819, and green sunfish, Lepomis cyanellus Rafinesque, 1819, were initially preserved for six weeks in a $10 \%$ formalin solution and then transferred to $70 \%$ ethyl alcohol for 46 additional weeks to determine how the commonly used preservation methods influence morphology. Fish were photographed at $0,3,6,12,24,39$, and 52 weeks of preservation to assess changes in shape. Standard length and maximum depth were measured on all fish images using Sigma Scan Pro. These measurements were then used to generate aspect ratios (maximum depth vs. standard length) for each fish. Additionally, geometric morphometric techniques (relative warp analysis) using 10 digital landmarks, were also used to evaluate overall morphological change.

Results. During the 52-week period of preservation, fish standard length was reduced, but this dimension shrank proportionally with body depth. This finding was confirmed along the major gradients elicited from relative warp axis scores tested using repeated measures ANOVA. However, with both species, morphological contortions were observed immediately after the fish were placed in formalin and again when this fixative was replaced with ethyl alcohol.

Conclusion. Ultimately, shape stabilized after a period of acclimatization of up to 39 weeks. This stabilization phenomenon provides evidence that long term museum collections do plateau in shape change and may be compared to address a variety of ecological and evolutionary hypotheses.
\end{abstract}

Keywords: fixation, geometric morphometrics, bluegill, green sunfish, body shape, formalin, ethyl alcohol

\section{INTRODUCTION}

The ability to make inferences of historical fish assemblages and adaptations to their environments is enhanced through the availability of museum collections (Suarez and Tsutsui 2004). Examining these collections allows identification or quantification of changes in species composition, biodiversity, biogeographic distributions, accumulation of toxins, and morphology across temporal and spatial scales. These changes can result from both natural and anthropogenic influences including channelization (Lau et al. 2006), water pollution (Hill et al. 2010), climate change, and modification of land use (Daniels et al. 2005). For example, museum specimens have been used to identify the accumulation of mercury in marine and freshwater fishes (Barber et al. 1972, Miller et al. 1972, Hill et al. 2010), the temporal change in Costa Rican fish assemblages (Reznick et al. 1994), and how an impoundment may result in the morphological divergence of a fish species (Franssen 2011). When museum specimens are available, our ability to make environmental and ecological inferences into the past on a wide array of topics is improved.

Maintaining museum specimens dictates that the fishes are preserved using procedures that promote long-term storage. Understanding the variety of preservation processes and the limitations they place on specimens is imperative to fully exploit the information contained in museum collections. Historically, formalin was used as a fixative and

\footnotetext{
* Correspondence: Dr. Thomas E. Lauer, Ball State University, Department of Biology, Cooper Life Science Building, Muncie, IN 47306, USA, e-mail: tlauer@bsu.edu.
} 
preservative; however, more recently this method changed given the toxicity of formalin (Morgan 1997) to using formalin for fixation and ethyl alcohol for preservation (Kelsch and Shields 1996, Al-Hassan et al. 2000). Regardless of the technique, the effects of preservation can be species- and size specific (Ehrlich 1974, Hjörleifsson and Klein-MacPhee 1992, Al-Hassan et al. 2000, Cunningham et al. 2000, Jawad 2003, Santos et al. 2009, Lee et al. 2011) or vary with the type of preservation (Cunningham et al. 2000, Jawad 2003, Santos et al. 2009).

The most common effect of preservation is shrinkage, potentially altering morphometric configurations (Al-Hassan et al. 2000, Cunningham et al. 2000, Lee et al. 2011). Shrinkage occurs when water is lost or replaced with preservative (Al-Hassan et al. 2000), albeit not all preservatives alter size and shape similarly. For example, ethanol causes a greater degree of shrinkage (Cunningham et al. 2000) when compared to buffered formalin (Moku et al. 2004). Further, freezing will also cause shrinkage due to evaporative loss, but no fluids are replaced (Jawad 2003).

Despite the abundance of information regarding fish shrinkage in length (Fox 1996, Al-Hassan et al. 2000, Jawad 2003, Thorstad et al. 2007) there is scant information on proportional shrinkage, that is, whether shrinkage occurs equally in all dimensions. Given the plethora of morphometric evaluations in population analysis (Meyer 1989, Reznick et al. 1994, Langerhans et al. 2003; AguilarMedrano et al. 2011, Franssen 2011), it is necessary to identify whether shrinkage of preserved specimens confounds morphometric analysis. Thus, the objectives of this study were:

- to identify whether bluegill, Lepomis macrochirus Rafinesque, 1819, and green sunfish, Lepomis cyanellus Rafinesque, 1819, retain their respective standard length and

- to quantify proportional morphologies, following preservation using formalin and ethyl alcohol.

We hypothesized that bluegill and green sunfish would shrink proportionally and stabilize on a scaled version of their respective fresh shapes.

\section{MATERIALS AND METHODS}

Collection, fixation, and preservation. Bluegill, Lepomis macrochirus $(n=34)$, and green sunfish, Lepomis cyanellus $(n=78)$, were collected in September 2010 from the Salamonie River, Jay County, Indiana, USA using a Smith-Root Model LR-24 backpack electrofisher. If hybridization was identified or suspected in a fish during collection, the fish was not included in the sample in order to eliminate the possibility of variation in morphology caused by hybridization. Following collection, fishes were measured (standard length, mm), photographed, and immediately fixed in buffered formalin (10\% formaldehyde) following Kelsch and Shields (1996). The left side of the fish was photographed using a Sony DSC W350 14MP camera with Zeiss MacroZoom lens in a lateral position against a grid background to facilitate scale reference. To avoid parallax, the same focal length was used in all photographs. After 3 weeks in buffered formalin, fishes were photographed as described above, and returned to the formalin. Following 6 weeks, fishes were photographed, placed in water for soaking until no formalin smell was observed, and transferred to $70 \%$ ethyl alcohol for long-term storage. Subsequent photographs were taken at $12,24,39$, and 52 weeks after the initial preservation.

This generalized methodology of preservation using formalin for fixing, water for clarification, and alcohol for longterm storage is typical (Etnier and Starnes 1993, Kelsch and Shields 1996, Hubbs and Lagler 2004, Simon 2011). We followed Kelsch and Shields (1996), as we needed to pick a single preservation method to satisfy our study objectives and to accurately represent a type of preservation currently used. Collection and handing protocol followed Animal Care and Use Committee guidelines of the Ball State University.

Standard length analysis. Standard length (SL) for each fish was measured from the photographs using Sigma Scan Pro for all seven time periods (i.e., 0, 3, 6 weeks, etc.). Standard length was used because it eliminates bias introduced into the measurements by torn, abraded, or damaged fins, particularly caudal fin tips, which could occur with handing during the study period. The SL unit of measure was a relative value generated by Sigma Scan, and by keeping the magnification of the photographs constant, proportional changes could be determined. At any time, absolute values ( $\mathrm{mm}$ ) for any dimension could be back calculated using the initial fresh SL measurements taken at the time of collection. A repeated measures ANOVA determined whether changes in SL occurred during the 52-week period while a post hoc Tukey test determined the time periods when shrinkage and stabilization occurred.

To align the variety of lengths found among fish used in the analysis and to provide an easier way to evaluate change over time, standard length measurements of fish were transformed using the formula:

$$
x=100 \mathrm{SL}_{\mathrm{w}} \cdot \mathrm{SL}_{0}{ }^{-1}
$$

where: $x=$ transformed length value; $\mathrm{SL}_{\mathrm{w}}=$ standard length $[\mathrm{mm}]$ for any given week; $\mathrm{SL}_{0}=$ standard length at week 0 .

Effectively, this transformation set the $\mathrm{SL}_{0}$ value at 100 with weeks 3-through-52 changes being expressed as percentages. For example, a value of 97 at three weeks would indicate a three percentage-point decrease in SL.

Aspect ratio analysis. Standard length and maximum depth of fish were measured from the photographs using Sigma Scan Pro using the methods described in the SL analysis above. From these measurements, the aspect ratio (maximum depth vs. standard length) was computed for all time periods and compared using a repeated measures ANOVA. Aspect ratio (proportional) data were arcsin transformed prior to analysis to establish normality (Zar 1999).

Relative warp analysis. Geometric morphometric methodologies (e.g., Procrustes technique) were used to describe the overall shape of each individual during the 
study period. Geometric morphometric methodologies represent an alternative to traditional truss style measurements (i.e., on bony structures or between fixed points) because multiple points of measurements are accounted for simultaneously to explain shape variation among individuals. Ten landmarks located at fixed locations on the fish (Fig. 1) were identified and digitized using the software tpsDig (ver. 2.11*). Relative warp analysis (RWA) using tpsRelW software (ver. $1.45^{*}$ ) was applied to quantify the diversity of shape variation based on acquired landmark data. The RWA extracts variation among landmark positions and results in a series of orthogonal axes interpreted using an eigenvalue and percent variation approach. Default settings were used in tpsRelW software including $\alpha=0$, complement uniform component, Chordmin BE slide method, and Slide $\max$ iters $=3$, Slide aligned $=1$, and orthogonal projection. To reduce the confounding effects of bending or arching that the majority of museum specimens exhibit during long term ethanol storage (Quicke et al. 1999), a series of 4 lateral landmarks (Fig. 1) was used, as reference points, to digitally unbend specimens using tpsUtil (ver. 1.46*). Differences in shape were identified using a random repeated measures general linear model whereby each individual was associated with seven measurements (e.g., RWA axis scores treated as repeated response variable) and compared by the time preserved (predictor variable) using SPSS-PASW 18*. Preservation time and fish number were set as fixed variables while body size and gender were set as covariates to reduce confounding effects of pseudoreplication, allometry, and sex in the model. The effects of pseudoreplication were addressed because identical treatments were applied to all specimens and the same individuals were analyzed at multiple periods of time (Hurlbert 1984). A post-hoc Tukey comparison was used to identify differences among preservation time periods. Alpha was set at 0.05 for all tests.

\section{RESULTS}

Standard length. Fish ranged in initial size from 54-164 $\mathrm{mm}$ SL for bluegill and 43-116 mm for green sunfish. After 52 weeks, bluegill ranged from 50-154 mm SL and green sunfish ranged from 43-118 mm SL. Fixation caused a six percentage-point decrease in mean SL for bluegill, and a two percentage-point decrease in mean SL for green sunfish. Bluegill SL stabilized after 24 weeks (Fig. 2; repeated measures ANOVA, $n=34, P<0.01$ ), while green sunfish SL stabilized after 12 weeks (Fig. 2; repeated measures ANOVA, $n=78, P<0.01$ ).

Aspect ratio. Bluegill aspect ratio ranged from 0.40-0.48 for fresh specimens, and from 0.43-0.48 following 52 weeks of fixation and preservation. Aspect ratio decreased initially, but by week 12 , rose back to the initial value where the aspect ratio remained through the rest of the 52-week study period (Fig. 3; repeated measures ANOVA; $n=34, P<0.01)$. Green sunfish aspect ratio ranged from $0.35-0.45$ initially, and from $0.36-0.45$ at 52 weeks. Aspect ratio in green sunfish did not change throughout the study period with the exception of week 24 where a slight decrease in values was found (Fig. 3; repeated measures ANOVA; $n=78, P<0.01)$.

Relative warp analysis. Bluegill body depth fluctuated during fixation and when switched to ethyl alcohol, but did not differ after 52 weeks of preservation (Fig. 4, Table 1; RWA1: ANOVA, $\left.F_{6,197}=10, R^{2}=0.34, P<0.001\right)$. However, the dorsal fin placement did shift from caudal (negative loading) to forward (positive loading) during the first six weeks, but did not significantly change thereafter (Table 1; RWA2: ANOVA, $F_{6,197}=5, R^{2}=0.16$, $P<0.001)$. This shift was seen by the movement of land-

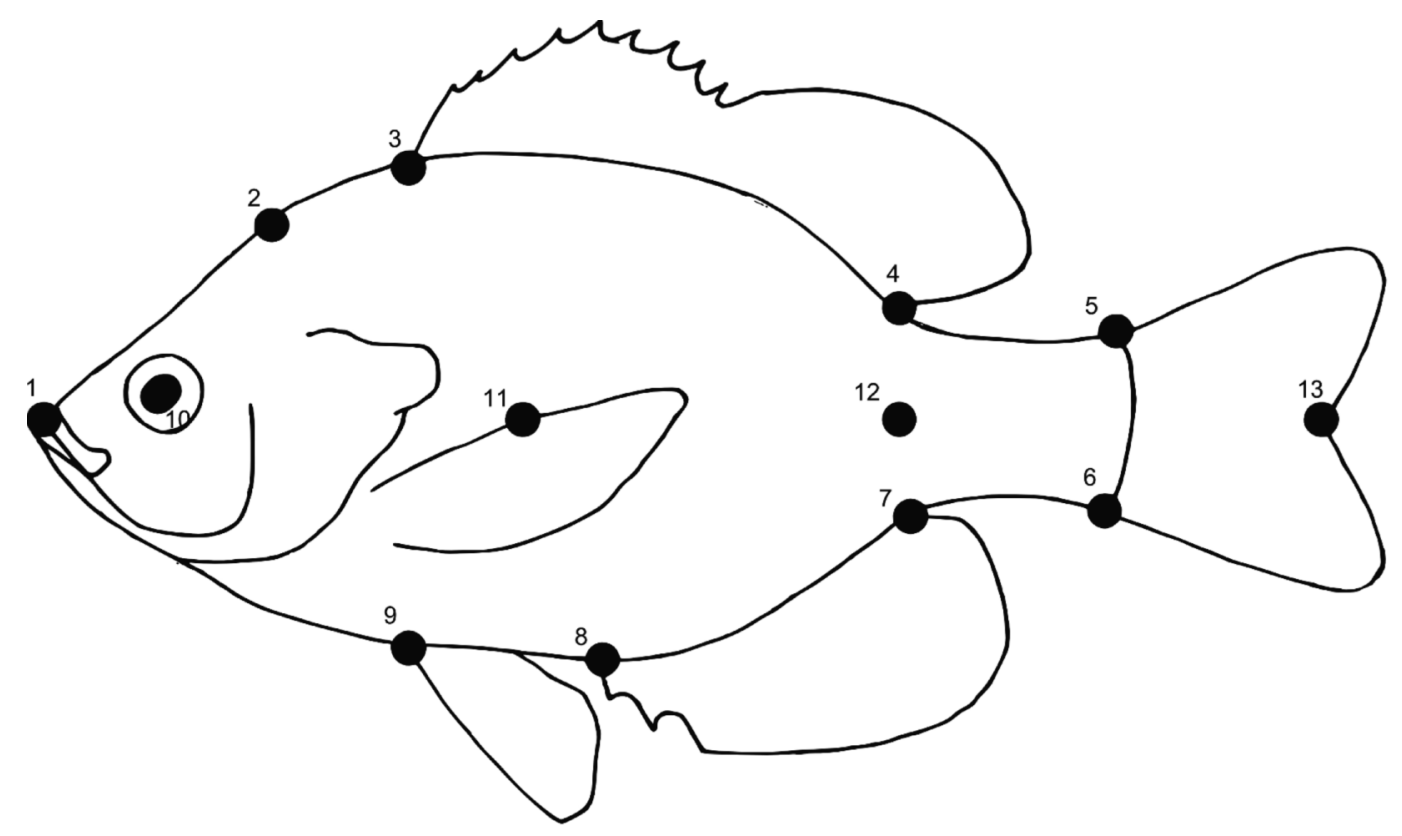

Fig. 1. Location of the 10 landmarks used to digitize images of fishes used in relative warp analyses; Landmarks 1, 11,12 , and 13 were used as reference points to digitally unbend specimens 
marks 3 and 4 (Fig. 1) moving towards the head (positive loading) and caudal (negative loading) regions over the first six weeks. The axis scores for RWA 3 did not vary during evaluation period (Table 1; RWA3: ANOVA, $\left.F_{6,196}=1, R^{2}=0.11, P>0.05\right)$.
Green sunfish had an increasingly fusiform shape in the first half of the time period resulting in a lower aspect ratio (Fig. 5, Table 2; RWA1: ANOVA, $F_{6,461}=23$, $\left.R^{2}=0.21, P<0.001\right)$. From 0 to 24 weeks, green sunfish showed an increasing head elongation and fusiform shape

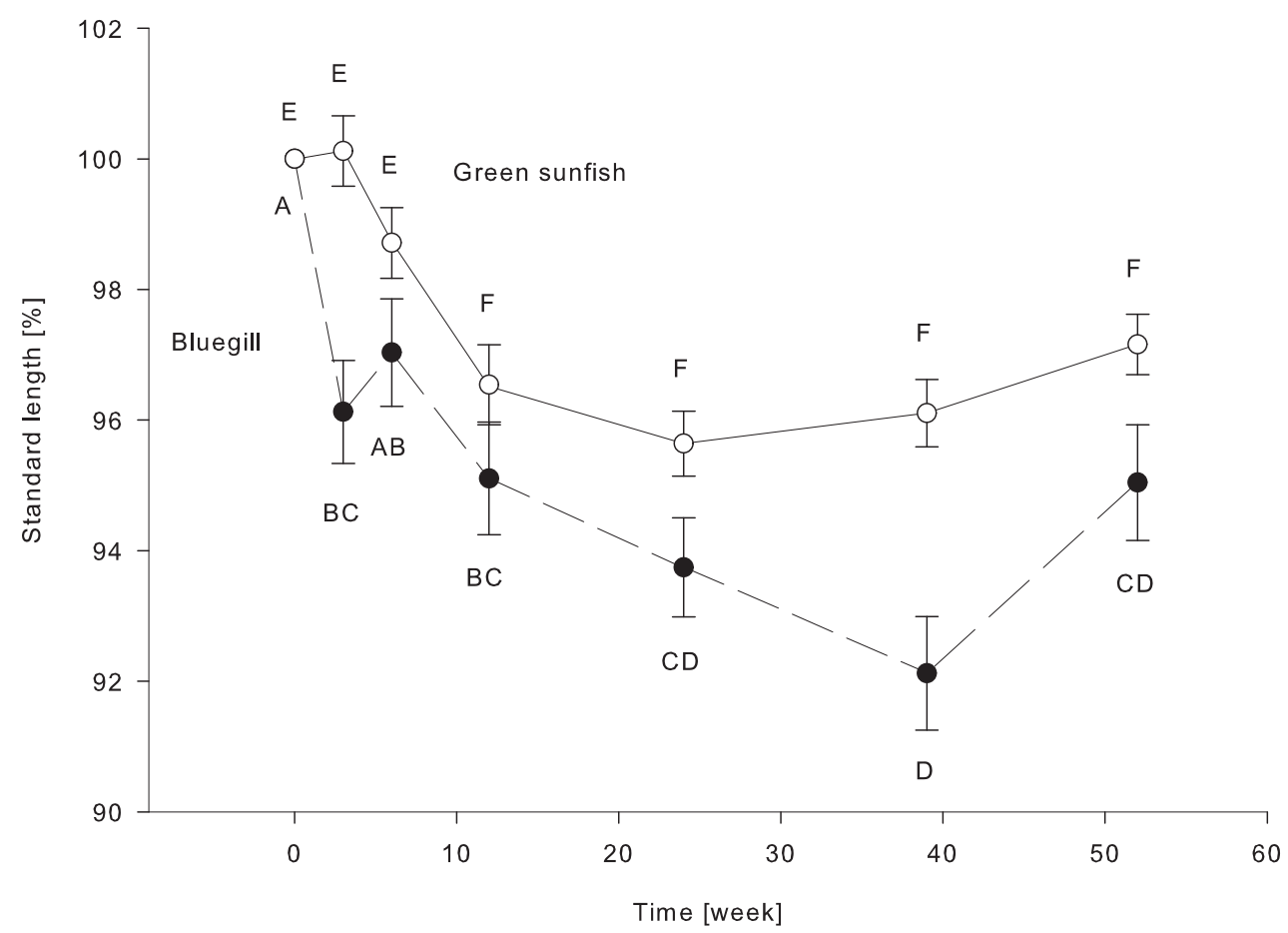

Fig. 2. Standard lengths for bluegill, Lepomis macrochirus $(n=34)$, and green sunfish, Lepomis cyanellus $(n=78)$, as a percentage of the initial length for each of the seven measurements made during the 52-week period; Values with similar letters are not significantly different $(P>0.05)$ based on a repeated measures ANOVA with post hoc Tukey comparisons

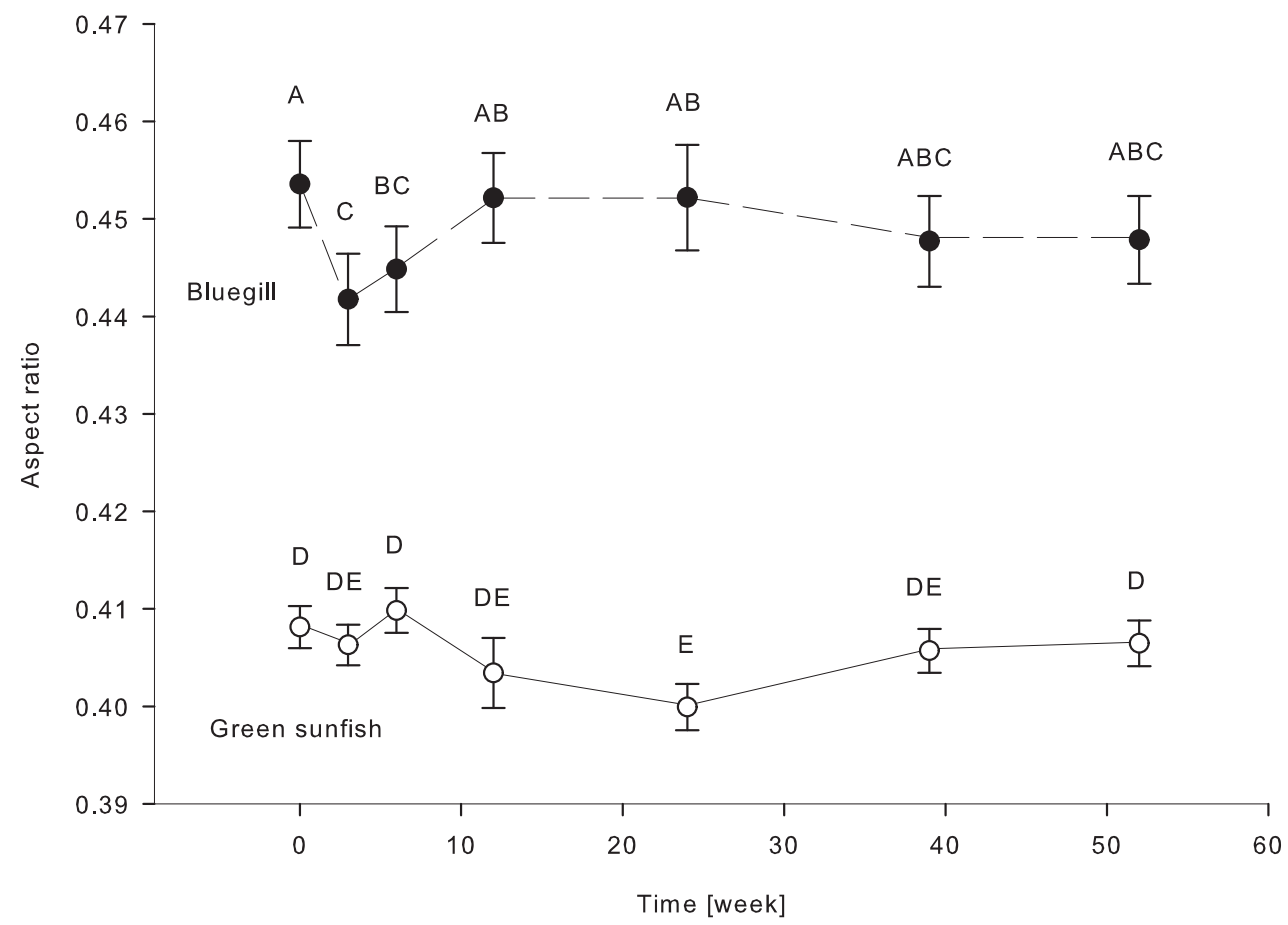

Fig. 3. Mean (SE) aspect ratios (maximum depth vs. standard length) of bluegill, Lepomis macrochirus $(n=34)$, and green sunfish, Lepomis cyanellus $(n=78)$, made during the 52-week period; Values with similar letters are not significantly different $(P>0.05)$ based on a repeated measures ANOVA with post hoc Tukey comparisons 
(positive loading) was identified in RWA2 that coincided with increasing preservation time (Fig. 5, Table 2; RWA2: ANOVA, $\left.F_{6,461}=18, R^{2}=0.19, P<0.001\right)$. Similarly, these changes were identified on axis RWA3 (Table 2; ANOVA, $F_{6,461}=12, R^{2}=0.15, P<0.001$ ) with a decreasing dorsal fin base and elongation of the caudal region (positive loading) until stabilizing at 12 weeks. The shape of fresh fish and those with short preservation times (i.e., 0-24 weeks) were significantly different from the shape of fish following longer preservation times, based on the caudal directional movement of the anal fin origin (positive loading) (Table 2; RWA4: ANOVA, $\left.F_{6,461}=9, R^{2}=0.11, P<0.001\right)$.

\section{DISCUSSION}

Identifying that shrinkage occurred with fish preservation confirms a number of recent studies (Fox 1996, Al-Hassan et al. 2000, Cunningham et al. 2000, Thorstad et al. 2007, Lee et al. 2011). However, our finding that a commonly used preservation methodology including fixative (formalin) and preservative (ethyl alcohol) (Kelsch and Shields 1996) shrinks fish proportionally along multidimensional planes has positive ramifications for morphological evaluations using preserved (e.g., museum) specimens. Although the amount of shrinkage may not be consistent among species, documentation associated with the fish at the time of preservation would

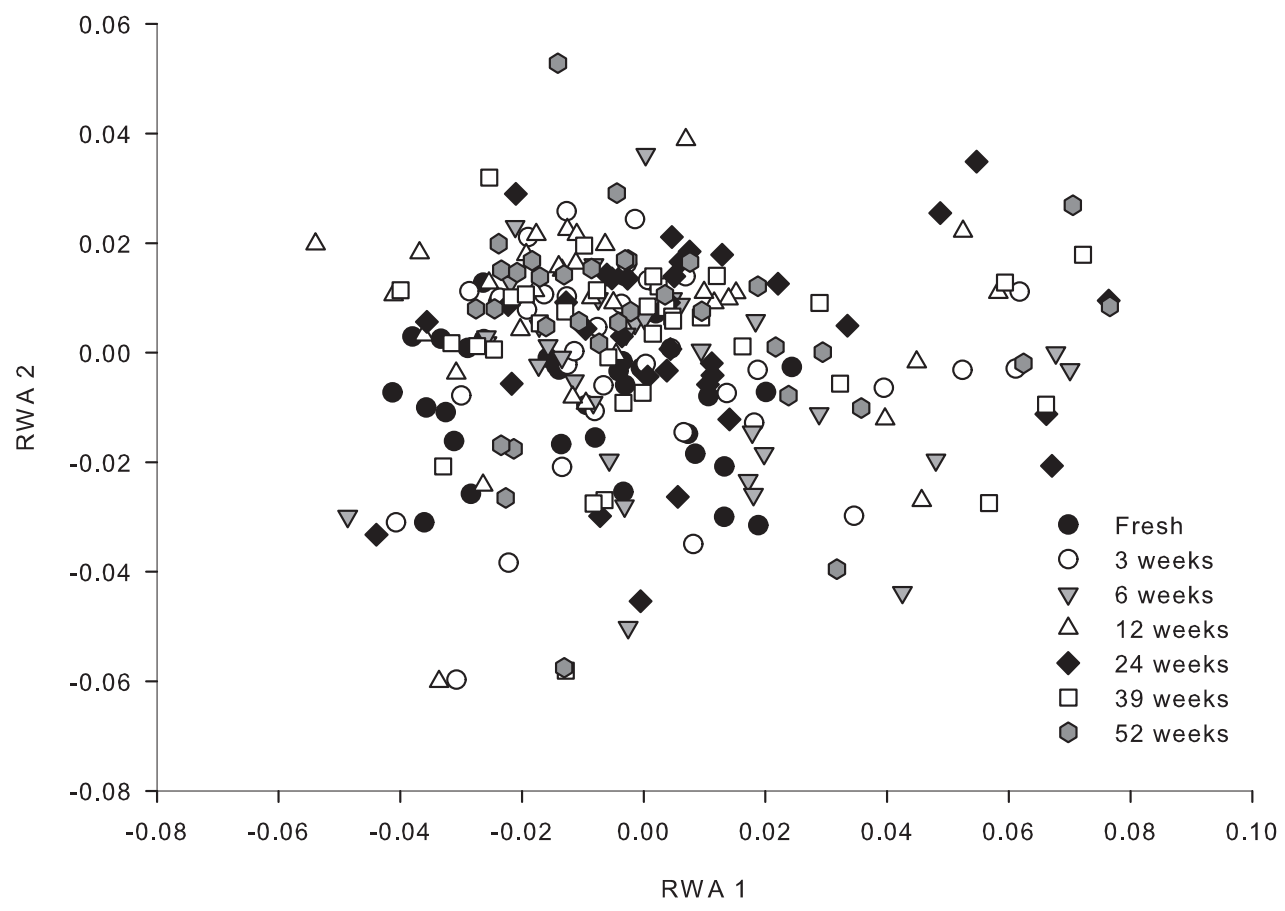

Fig. 4. Relative warp analysis (RWA) results comparing RWA 1 and RWA 2 for bluegill, Lepomis macrochirus, at 0 , $3,6,12,24,39$, and 52 weeks

Table 1

General linear model results of relative warp analysis (RWA) axis scores for each of the seven measurement periods during the 52 weeks of study of bluegill, Lepomis macrochirus, along with post hoc Tukey comparison

\begin{tabular}{cccc}
\hline $\begin{array}{c}\text { Preservation } \\
\text { Time (week) }\end{array}$ & $\begin{array}{c}\text { RWA1 } \\
\text { Mean (SD) }\end{array}$ & $\begin{array}{c}\text { RWA2 } \\
\text { Mean (SD) }\end{array}$ & $\begin{array}{c}\text { RWA3 } \\
\text { Mean }(\mathrm{SD})\end{array}$ \\
\hline 0 & $-0.011(0.02) \mathrm{B}$ & $-0.008(0.01) \mathrm{B}$ & $0.001(0.02) \mathrm{A}$ \\
3 & $0.000(0.03) \mathrm{A}$ & $-0.003(0.02) \mathrm{AB}$ & $0.008(0.02) \mathrm{A}$ \\
6 & $0.0(0.03) \mathrm{A}$ & $-0.004(0.02) \mathrm{AB}$ & $0.002(0.02) \mathrm{A}$ \\
12 & $-0.005(0.03) \mathrm{B}$ & $0.007(0.02) \mathrm{A}$ & $-0.005(0.02) \mathrm{A}$ \\
24 & $0.008(0.03) \mathrm{A}$ & $0.002(0.02) \mathrm{A}$ & $-0.003(0.01) \mathrm{A}$ \\
39 & $0.002(0.03) \mathrm{AB}$ & $0.001(0.02) \mathrm{AB}$ & $0.001(0.01) \mathrm{A}$ \\
52 & $0.002(0.03) \mathrm{AB}$ & $0.005(0.02) \mathrm{A}$ & $-0.003(0.01) \mathrm{A}$ \\
\hline
\end{tabular}

Values with similar letters are not significantly different $(P>0.05)$. 
typically include a length measurement (Kelsch and Shields 1996). This metric, along with the preserved length, could be used to calibrate other fish dimensions knowing that shrinkage was proportional.

Standard length shrinkage for bluegill (6 percentage points) and green sunfish (2 percentage points) was expected, but the expected amount of shrinkage for both species was initially unknown. Anderson and Neumann (1996) suggest length will decrease 2 percentage points over 10 days when fish are preserved in 10\% formalin and stabilize thereafter. The size reduction in green sunfish was similar to their expectations, in contrast to bluegill where the fish was reduced over twice the predicted values. Differences also occurred in the timing of shrinkage, with standard length occurring in bluegill within the first three weeks as suggested by Anderson and Neumann (1996), although some fluctuations were seen throughout the 52 week period. In contrast, it took green sunfish 12 weeks to stabilize, but this fish did not demonstrate the length fluctuations found in bluegill. These changes suggest that as specimens are moved from a fixative to a preservative, they have the potential to experience further shape alteration, and require additional time for shape stabilization. The time of secondary stabilization for ethyl alcohol was approximately 12 weeks. Because the two species have similar body plans and are phylogenetically close (Avise and Smith 1977), we expected similar patterns of size change. Further, we suggested shrinkage

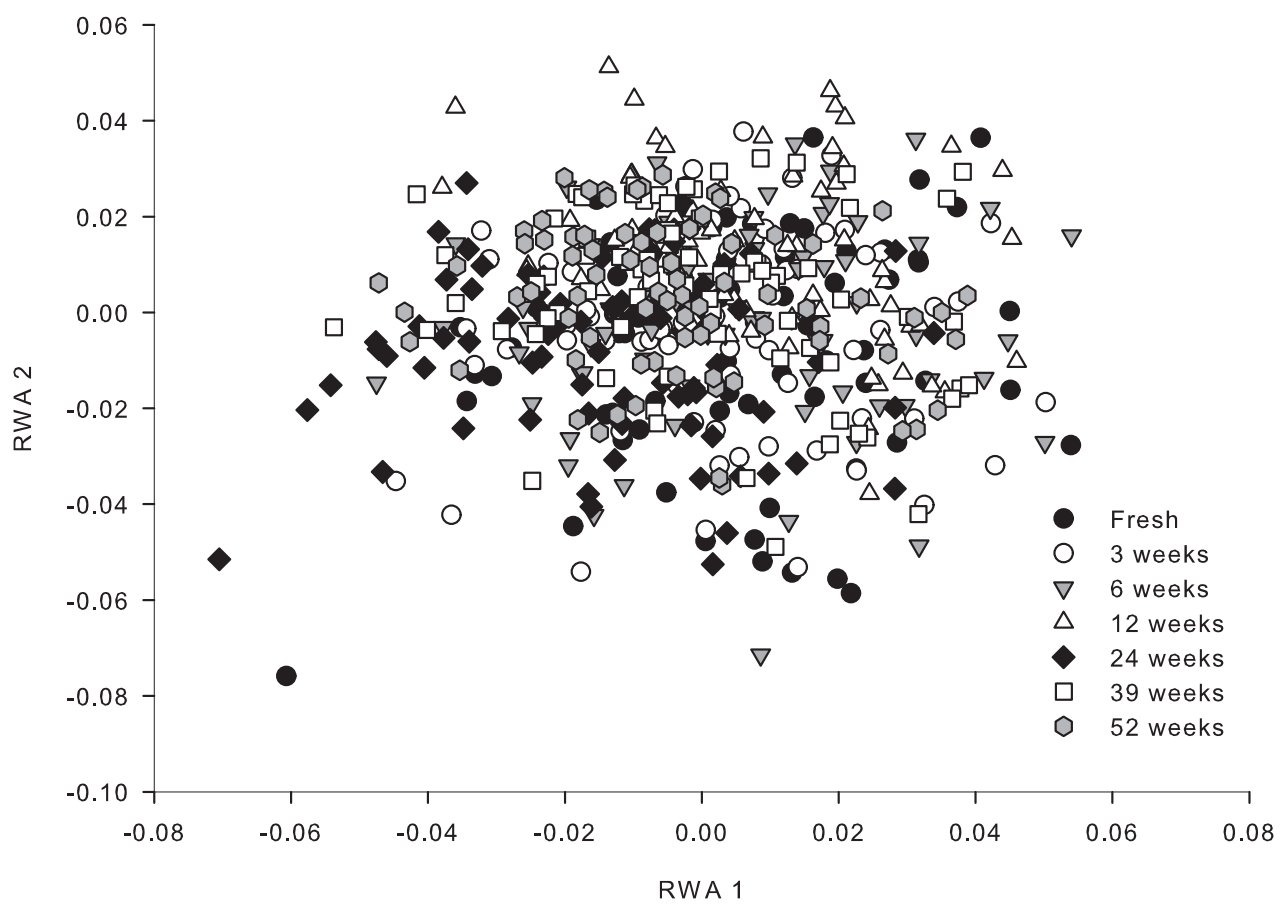

Fig. 5. Relative warp analysis (RWA) results comparing RWA 1 and RWA 2 for green sunfish, Lepomis cyanellus, at $0,3,6,12,24,39$, and 52 weeks

General linear model results of relative warp analysis (RWA) axis scores for each of the seven measurements made during the 52 week period of studying green sunfish, Lepomis cyanellus, along with post hoc Tukey comparisons

\begin{tabular}{ccccc}
\hline $\begin{array}{c}\text { Preservation } \\
\text { Time (week) }\end{array}$ & RWA1 & RWA2 & RWA3 & $\begin{array}{c}\text { RWA4 } \\
\text { Mean (SD) }\end{array}$ \\
\hline 0 & $0.005(0.02) \mathrm{A}$ & $-0.007(0.02) \mathrm{C}$ & $-0.006(0.02) \mathrm{C}$ & $0.006(0.02) \mathrm{A}$ \\
3 & $0.002(0.02) \mathrm{AB}$ & $-0.003(0.02) \mathrm{BC}$ & $-0.005(0.02) \mathrm{C}$ & $0.005(0.01) \mathrm{AB}$ \\
6 & $0.004(0.02) \mathrm{A}$ & $-0.002(0.02) \mathrm{BC}$ & $-0.004(0.02) \mathrm{C}$ & $0.005(0.01) \mathrm{A}$ \\
12 & $0.007(0.02) \mathrm{A}$ & $0.013(0.02) \mathrm{A}$ & $0.006(0.02) \mathrm{A}$ & $0.002(0.01) \mathrm{AB}$ \\
24 & $-0.014(0.02) \mathrm{C}$ & $-0.008(0.02) \mathrm{C}$ & $0.001(0.02) \mathrm{B}$ & $-0.008(0.02) \mathrm{C}$ \\
39 & $-0.001(0.02) \mathrm{AB}$ & $0.004(0.02) \mathrm{B}$ & $0.004(0.02) \mathrm{AB}$ & $-0.003(0.01) \mathrm{BC}$ \\
52 & $-0.004(0.02) \mathrm{B}$ & $0.003(0.02) \mathrm{B}$ & $0.005(0.02) \mathrm{A}$ & $-0.007(0.01) \mathrm{C}$ \\
\hline
\end{tabular}

Values with similar letters are not significantly different $(P>0.05)$. 
might take up to 24 weeks for stabilization of these species. Given the magnitude of differences found in these two congeneric fishes, we recommended that species-specific shrinkage be identified for all fishes, particularly when preserved fish are compared with fresh specimens.

Aspect ratios changed somewhat during the 52-week preservation period, but the initial and final aspect ratios remained unchanged (Fig. 3). These findings suggested that body depth shrinks proportionally with length and provides evidence that morphology changes with preservation are not simply one-dimensional. Unfortunately, our findings are limited by the planar image of the photograph where the measurements were taken. Preservation can also increase fish weight (Yeh and Hodson 1975, Billy 1982) by increasing girth despite length and depth being reduced. Thus, extending our inference to width is not possible or realistic.

We identified changes to specific regions of the fish's morphology (i.e., fin placement) that coincided with preservation methodology and time using RWA. However, the RWA in bluegill did show that body shape, exclusive of fin placement, remained proportional after preservation and was similar to results identified in our aspect ratio analysis. Although the first axis showed fluctuation in body depth during fixation, these changes occurred during the intermediate time intervals of the analysis while the fresh and 52-week morphologies did not differ (Table 1). Green sunfish, conversely, differed across all four axes (Table 2). The changes during the intermediate time intervals are likely caused by the change from fixative to preservative.

Discrepancies, however, have been demonstrated in species specific measurement changes found with preservation. Engel (1974), Hunter (1985), and Sayers (1987) described a decrease in the total length of lake cisco, Coregonus artedi Lesueur, 1818; yellow perch, Perca flavescens (Mitchill, 1814); Californian anchovy, Engraulis mordax Girard, 1854; and Lake Michigan bloaters, Coregonus hoyi (Milner, 1874); respectively. In contrast, Billy (1982), Al-Hassan and Abdullah (1992), and Al-Hassan et al. $(1999,2000)$ suggested that there was a slight increase in standard length or no shrinkage in specimens preserved in formalin and ethyl alcohol based on Mosambique tilapia, Oreochromis mossambicus (Peters, 1852); himri, Barbus luteus (Heckel, 1843); and Indian mackerel, Rastrelliger kanagurta (Cuvier, 1816); respectively. Our disparate findings on the time and amount of shrinkage using two similar species confirm that the response to preservation is species-specific. Thus, when introducing any alternative preservation, it may not be possible to predict the morphological changes to the specimen.

The value of preserved and deposited organisms cannot be understated as these museum specimens make an ongoing contribution toward our understanding and advancement of science. Although the preservation process may alter morphology, efforts to define and detail the limitations that preservation places on historical collections are necessary. Despite the problems with preser- vation, this process allows examination post mortem and is often a study necessity. Further, by comparing fresh and preserved specimens, we can additionally identify the bias induced by preservation (Fey 1999, Porter et al. 2001, Santos et al. 2005) that confounds accuracy and precision of measurement. This study suggests that bias on a planar image is minimal or non-existent, and that these findings will advance our abilities to study and evaluate morphology of preserved specimens. Finally, we suggest that future studies are warranted on all museum specimens and preservation techniques to further enhance our understanding of these valuable resources.

\section{ACKNOWLEDGEMENTS}

We thank M. Allen, C. Carpenter, B. Ciara, C. Miller, and $\mathrm{K}$. Rounds for their assistance in collecting our samples. We thank the Ball State University for funding this research project. This study was presented at the 142nd annual meeting of the American Fisheries Society (MN, USA 2012).

\section{REFERENCES}

Aguilar-Medrano R., Frédérich B., de Luna E., Balart E.F. 2011. Patterns of morphological evolution of the cephalic region in damselfishes (Perciformes: Pomacentridae) of the Eastern Pacific. Biological Journal of the Linnean Society 102 (3): 593-613. DOI: 10.1111/j.1095-8312.2010.01586.x

Al-Hassan L.A.J., Abdullah J.N. 1992. The effect of formalin and some body proportions of Barbus luteus. Pakistan Journal of Zoology 24 (1): 353-354.

Al-Hassan L.A.J., Bujawari J.A., El-Silini O.A. 2000. The effect of some preservatives and freezing on certain body dimensions of two species of the family Mullidae collected from Benghazi waters, Libya. Acta Ichthyologica et Piscatoria 30 (2): 127-136.

Al-Hassan L.A.J., Bujawari J.A., El-Siline O.A. 1999. Additional report on the effect of preservatives and freezing on morphological characters of four sparid fish species collected from Benghazi, Libya. Journal of Animal Morphology and Physiology 46 (1-2): 57-62.

Anderson R.O., Neumann R.M. 1996. Length, weight, and associated structural indices. Pp. 447-481. In: Murphy B.R., Willis D.W. (eds.) Fisheries Techniques (2nd edn.). American Fisheries Society, Bethesda.

Avise J.C., Smith M.H. 1977. Gene frequency comparisons between sunfish (Centrarchidae) populations at various stages of evolutionary divergence. Systematic Biology 26 (3): 319-335. DOI: 10.1093/sysbio/26.3.319

Barber R.T., Vijayakumar A., Cross F.A. 1972. Mercury concentration in recent and ninety-year old benthopelagic fish. Science 178 (4061): 636-639. DOI: 10.1126/science. 178.4061 .636

Billy A.J. 1982. The effect of formalin and isopropyl alcohol on length and weight measurements of Sarotherodon mossambicus Trewavas. Journal of Fish Biology 21 (1): 107-112. DOI: $10.1111 /$ j.1095-8649.1982.tb02828.x

Cunningham M.K., Granberry W.F., Pope K.L. 2000. Shrinkage of inland silverside larvae preserved in ethanol 
and formalin. North American Journal of Fisheries Management 20 (3): 816-818. DOI: 10.1577/15488675(2000)020<0816:SOISLP $>2.3 . C O ; 2$

Daniels R.A., Limburg K.E., Schmidt R.E., Strayer D.L., Chambers R.C. 2005. Changes in fish assemblages in the tidal Hudson River, New York. Pp. 471-503. In: Rinne J.N., Hughes R.M., Calamusso B. (eds.). Historical changes in large river fish assemblages of America. American Fisheries Society Symposium Vol. 45.

Ehrlich K.F. 1974. Chemical changes during growth and starvation of herring larvae. Pp. 301-324. In: Blaxter J.H.S. (ed.) The early life history of fish. Springer-Verlag, Berlin and New York.

Engel S. 1974. Effects of formalin and freezing on length, weight and condition factor of cisco and yellow perch. Transactions of the American Fisheries Society 103 (1): 136-138. DOI: $10.1577 / 1548-8659(1974) 103<136$ : EOFAFO $>2.0 . \mathrm{CO} ; 2$

Etnier D.A., Starnes W.C. 1993. The fishes of Tennessee. University of Tennessee Press, Knoxville, TN, USA.

Fey D.P. 1999. Effects of preservation technique on the length of larval fish: methods of correcting estimates and their implication for studying growth rates. Archive of Fishery and Marine Research 47: 17-29.

Fox C.J. 1996. Length changes in herring (Clupea harengus) larvae: effects of capture and storage in formaldehyde and alcohol. Journal of Plankton Research 18 (4): 483-493. DOI: $10.1093 /$ plankt/18.4.483

Franssen N.R. 2011. Anthropogenic habitat alterations induces rapid morphological divergence in a native stream fish. Evolutionary Applications 4 (6): 791-804. DOI: 10.1111/j.1752-4571.2011.00200.x

Hill J.J., Chumchal M.M., Drenner R.W., Pinder III J.E., Drenner S.M. 2010. Use of preserved museum fish to evaluate historical and current mercury contamination in fish from two rivers in Oklahoma, USA. Environmental Monitoring and Assessment 161 (1-4): 509-516. DOI: 10.1007/s10661-009-0764-5

Hjörleifsson E., Klein-MacPhee G. 1992. Estimation of live standard length of winter flounder Pleuronectes americanus larvae from formalin-preserved, ethanol-preserved and frozen specimens. Marine Ecology Progress Series 82: 13-19.

Hubbs C.L., Lagler K.F. 2004. Fishes of the Great Lakes Region, revised by Smith G.R. The University of Michigan Press, Ann Arbor, MI, USA.

Hunter J.R. 1985. Preservation of northern anchovy in formaldehyde solution. NOAA Technical Report NMFS 36: 63-65.

Hurlbert S.H. 1984. Pseudoreplication and the design of ecological field experiments. Ecological Monographs 54 (2): 187-211. DOI: $10.2307 / 1942661$

Jawad L.A. 2003. The effect of formalin, alcohol and freezing on some body proportions of Alepes djedaba (Pisces: Carangidae) collected from the Red Sea coast of Yemen. Revista de Biología Marina y Oceanografía 38 (2): 77-80.

Kelsch S.W., Shields B. 1996. Care and handling of sampled organisms. Pp. 121-155. In: Murphy B.R., Willis D.W. (eds.)
Fisheries Techniques (2nd edn.). American Fisheries Society, Bethesda, MD, USA.

Langerhans R.B., Layman C.A., Langerhans A.K., DeWitt T.J. 2003. Habitat-associated morphological divergence in two Neotropical fish species. Biological Journal of the Linnean Society 80 (4): 689-698. DOI: $10.1111 /$ j.10958312.2003.00266.X

Lau J.K., Lauer T.E., Weinman M.L. 2006. Impacts of channelization on stream habitats and associated fish assemblages in East Central Indiana. American Midland Naturalist 156 (2): 319-330. DOI: 10.1674/0003-0031(2006) 156[319:IOCOSH]2.0.CO;2

Lee J.-H., Kodama K., Horiguchi T. 2011. Change in body size of juvenile marbled sole Pseudopleuronectes yokohamae after preservation in ethanol. Ichthyological Research (1): 49-52. DOI: 10.1007/s10228-011-0255-x

Meyer A. 1989. Cost of morphological specialization: Feeding performance of the two morphs in the trophically polymorphic cichlid fish, Cichlasoma citrinellum. Oecologia 80 (3): 431-436. DOI: 10.1007/BF00379047

Miller G.E., Grant P.M., Kishore R., Steinkruger F.J., Rowland F.S., Guinn V.P. 1972. Mercury concentrations in museum specimens of tuna and swordfish. Science $\mathbf{7 5}$ (4026): 1121-1122. DOI: 10.1126/science.175.4026.1121

Moku M., Mori K., Watanabe Y. 2004. Shrinkage in the body length of myctophid fish (Diaphus slender-type spp.) larvae with various preservatives. Copeia 2004 (3): 647-651. DOI: 10.1643/CI-03-113R

Morgan K.T. 1997. A brief review of formaldehyde carcinogenesis in relation to rat nasal pathology and human health risk assessment. Toxicologic Pathology 25 (3): 291-305. DOI: $10.1177 / 019262339702500307$

Porter S.M., Brown A.L., Bailey K.M. 2001. Estimating live standard length of net-caught walleye pollock (Theragra chalcogramma) larvae using measurements in addition to standard length. Fishery Bulletin 99 (4): 691-696.

Quicke D.L.J., Lopez-Vaamonde C., Belshaw R. 1999. Preservation of hymenopteran specimens for subsequent molecular and morphological study. Zoologica Scripta 28 (1-2): 261-267. DOI: 10.1046/j.1463-6409.1999.00004.x

Reznick D., Baxter R.J., Endler J. 1994. Long-term studies of tropical stream fish communities: The use of field notes and museum collections to reconstruct communities of the past. American Zoologist 34 (3): 452-462. DOI: 10.1093/icb/34.3.452

Santos J.N.S., Araújo F.G., Silva D.S. 2009. Length correction for early-juvenile Brazilian herring Sardinella janeiro (Eigenmann, 1894) after preservation in formalin, ethanol, and freezing. Neotropical Ichthyology 7 (1): 87-92. DOI: 10.1590/S1679-62252009000100011

Santos J.N.S., Silva M.A., Vasconcellos R.M., Araújo F.G. 2005. Efeito do tempo de conservação dos espécimes sobre a qualidade dos microincrementos em otólitos sagittae de Anchoa tricolor (Agassiz) (Clupeiformes, Engraulidae). Effect of the conservation period of the specimens on the microstructure quality of sagittae otoliths in Anchoa tricolor (Agassiz) (Clupeiformes, Engraulidae). Revista Brasileira de Zoologia 22 (4): 949-952. [In Portuguese.] DOI: 10.1590/S0101-81752005000400022 
Sayers R.E. 1987. Effects of freezing in and out of water on length and weight of Lake Michigan bloaters. North American Journal of Fisheries Management 7 (2): 299-301. DOI: $10.1577 / 1548-8659(1987) 7<299$ :EOFIAO $>2.0 . C O ; 2$

Simon T.P. 2011. Fishes of Indiana. Indiana University Press, Bloomington, IN, USA.

Suarez A.V., Tsutsui N.D. 2004. The value of museum collections for research and society. BioScience 54 (1): 66-74. DOI: 10.1641/0006-3568(2004)054[0066:TVOMCF]2.0. $\mathrm{CO} ; 2$

Thorstad E.B., Finstad A.G., Jensen A.J., Museth J., Nasje T.F., Saksgård L.M. 2007. To what extent does ethanol and freezing preservation cause shrinkage of juvenile Atlantic salmon and European minnow? Fisheries Management and Ecology 14 (4): 295-298. DOI: 10.1111/j.1365-2400. 2007.00553.x

Yeh C.F., Hodson R.G. 1975. Effects of formalin on length and weight of bluegill and white crappie from Lake Nasworthy, Texas. Southwestern Naturalist 20 (3): 315-322.

Zar J.H. 1999. Biostatistical analysis. Prentiss Hall, Upper Saddle River, NJ, USA.

Received: 24 April 2013

Accepted: 5 September 2013

Published electronically: 30 September 2013 